\title{
Short Communication: Isolation and screening of polyhydroxylalkanoates producing microorganisms from Thailand
}

\author{
NUNTAPORN PUNGSUNGVORN", ANUSSORN WISETSING \\ Department of Biotechnology, Faculty of Science and Technology, Rajamangala University of Technology Tawan-ok. 43 Moo 6, Bang Phra, Sriracha, \\ Chonburi 20110, Thailand. Tel.: +66-863212464; Fax.: +66-863212464, `email: nuntaporn_pu@rmutto.ac.th
}

Manuscript received: 6 September 2021. Revision accepted: 23 October 2021.

\begin{abstract}
Pungsungvorn N, Wisetsing A. 2021. Short Communication: Isolation and screening of polyhydroxylalkanoates producing microorganisms from Thailand. Biodiversitas 22: 4963-4967. Polyhydroxylalkanotes (PHAs) are polyesters produced in nature by numerous microorganisms. They are biodegradable and are used in the production of bioplastics. In this study, one hundred twenty samples from different regions of Thailand were collected and screened for polyhydroxylalkanoates (PHAs) producing microorganisms. The samples were screened on YM agar containing $0.5 \mu \mathrm{g}$ Nile-red/mL (YM-NR). Only one isolate of yeast (Y1) gave a positive result on PHA accumulation. The yeast isolate (Y1) was identified as Candida tropicalis by API 20C AUX kit and 18S rRNA nucleotide comparison. The yeast isolate $\mathrm{Y} 1$ produced $2.62 \%$ PHA when grown in synthetic N-limiting medium using rice straw hydrolysate as carbon source. The selected four bacteria (B1, B2, B3 and B4) were identified by BlastN of 16S rRNA as Enterobacter cloacae, Enterobacter carcerogenus, Escherichia coli and Klebsiella pneumonia, respectively. The selected yeast and bacterial strains gave PHA content of 2.62, 2.76, 5.38, 3.66 and $0.44 \%$, respectively, in synthetic N-limiting medium using rice straw hydrolysate. Hence, these microorganisms could be used in PHA production from biomass in the future.
\end{abstract}

Keywords: Biodiversity, bioplastic, PHA, polyester, rice straw

\section{INTRODUCTION}

Plastics and pollution are two deeply connected terms. Millions tons of nondegradable plastics accumulate in the environment per year. It can cause serious environmental problems to the world, especially green house effect. Currently, the use of bioplastics is continuously increasing around the world. Bioplastics are plastics that are naturally biodegradable and are used as a substitute for plastics made from petrochemicals. Scientists pay attention to the development of natural and environmentally friendly materials for bioplastics applications. Among these materials, polyhydroxyalkanoic acids or polyhydroxylalkanoates (PHAs) are very interesting because PHAs are similar to petrochemical polyester with good formability. PHAs have interesting properties of bioplastics production since PHAs are thermoplastic, gas barrier, UV resistant, biocompatible, elastic, rigid and hydrophobic. PHAs are eco-friendly, $100 \%$ biodegradable, recyclable, non-toxic, biocompatible, and biodegradable (Anjum et al. 2016). PHAs are biodegradable in both soil and water environments and can be composted by biological methods which are found to be completely decomposed within 49 days (Folino et al. 2020; Karan et al. 2019). PHAs can be used for both medical and industrial applications.

PHAs are biopolyesters found in microorganisms, such as bacteria (Alcaligenes latus, Ralstonia eutropha, Azotobacter beijerinckii, Bacillus megaterium, Aeromonas hydrophila, Cupriavidus necator and Pseudomonas oleovorans), yeast (Arxula adeninivorans, Rhodotorula minuta) and blue-green algae (Chlorogloea fritschii, Gloeocapsa strain 6501) (Anjum et al. 2016; Tan et al. 2019). PHAs are accumulated in cells as granules in the cytoplasm. PHAs are composed of hydroxyalkanoate units and can be classified according to the number of carbon atoms present in the monomer units into two groups: medium chain length PHAs consist of 6-14 carbon atoms, e.g. poly-3-hydroxybutyrate-co-3-hydroxyvalerate copolymer [P(3HB-co-3HV)], and short chain length PHAs consist of 3-5 carbon atoms, e.g. poly-3-hydroxybutyrate [P(3HB)] (Ciesielski et al. 2015). The composition of PHA is clearly affected by the choice of the microorganism and the carbon source (Anjum et al. 2016). PHAs consist of several types of hydroxycarboxylic acid polyesters which are produced by large number of bacteria. It is a hydrophobic aggregation that occurs in bacterial cells with excess carbon and other nutrient restrictions such as N, P, S or $\mathrm{Mg}$. They are used as carbon reserves and energy (Anjum et al. 2016). PolyFerm Canada, a Canadian bioplastics company, uses Aeromonas hydrophila and Pseudomonas putida for industrial production of PHA. Tianan Biologic, a Chinese company, also uses Cupriavidus necator for industrial production (Pakalapati et al. 2018). However, the cost of production is 5-10 times more expensive than conventional plastic (Anjum et al. 2016). Raw material, carbon sources cost more than $50 \%$ of the process and therefore tend to switch to cheap, waste and sustainable substrates that are easily processed or require no processing (Pakalapati et al. 2018). The carbon source used in the production of PHA can be divided into 6 
groups namely, starch-based media, sugar-based media, cellulosic and hemicellulosic media, whey-based media, oil-based media and glycerol-based media (Amache et al. 2013). Various types of waste products are used for PHB production because it provides dual benefits of utilizing the waste and cost-effective production of biodegradable microbial bioplastic (Anjum et al. 2016). In this study, PHAs producing microorganisms were isolated and screened using rice straw hydrolysate as a sole carbon source with the dual benefit of utilizing the waste and costeffective production of biodegradable microbial bioplastic.

\section{MATERIALS AND METHODS}

\section{Samples}

One hundred twenty samples of soils, leaves, fruits, flowers and agricultural wastes (10 samples from each province: Chonburi, Chachoengsao, Rayong, Chanthaburi, Trat, Prachinburi, Sa Kaeo, Lampang, Phuket, Phra Nakhon Si Ayutthaya, Khon Kaen, and Ratchaburi, Thailand) were collected and used as source for isolation of PHA producing microorganisms. The samples were kept in refrigerator for further analysis.

\section{Isolation and screening}

The sample, $1 \mathrm{~g}$ of solid sample was suspended in $5 \mathrm{~mL}$ YM broth (containing (in $\mathrm{g} / \mathrm{L}$ ) glucose 10, malt extract 3, peptone 5 , yeast extract 3 ) and incubated at $30^{\circ} \mathrm{C}, 18-24 \mathrm{hr}$ for enrichment (Abd-El-Haleem 2009). The enriched broth was spread on YM agar and incubated at $30^{\circ} \mathrm{C}, 18-24 \mathrm{hr}$. The selected colonies were maintained in YM slant and $15 \%$ glycerol for further study. The isolates were screened for PHA production on YM agar containing $0.5 \mu \mathrm{g}$ Nile$\mathrm{red} / \mathrm{mL}$ (YM-NR) at $30^{\circ} \mathrm{C}$ (Abd-El-Haleem et al. 2007b). The PHA accumulation was observed under ultraviolet light every 24 h, for 6 days (Spiekermann et al. 1999).

\section{Morphological and molecular identification}

The morphology of the selected strains were observed under microscope. The selected strains were cultured in YM broth and genomic DNA was extracted using Wizard Genomic DNA Purification kit (Promega). The 18S rRNA and 16S rRNA were amplified and cloned from yeast isolate and bacteria isolates, respectively (Abd-El-Haleem 2009; Martı'nez-Gutie'rrez et al. 2018; Tan et al. 2019). The $18 \mathrm{~S}$ rRNA and 16S rRNA gene were sequenced and subjected to BlastN search at www.ncbi.nlmnih.gov/blast for identification.

\section{Rice straw hydrolysate preparation}

Rice straw was pretreated by drying in hot air oven at $60^{\circ} \mathrm{C}$ for $12 \mathrm{~h}$ and grinded with blender. The rice straw powder was soaked in $2 \%$ hydrogenperoxide, $\mathrm{pH} 11.5$ at ratio $1 \mathrm{~g}: 10 \mathrm{~mL}$ at $35^{\circ} \mathrm{C}$ for $24 \mathrm{~h}$. The powder was filtered, washed with distilled water and dried at $60^{\circ} \mathrm{C}$ for $12 \mathrm{~h}$. The rice straw powder was kept in cool and dry place for further study.

For hydrolysis, rice straw powder was hydrolyzed with $2 \%$ sulfuric acid at ratio $1 \mathrm{~g}: 10 \mathrm{~mL}$ at $121^{\circ} \mathrm{C}$ for $15 \mathrm{~min}$. The hydrolysate was separated by filtration and $\mathrm{pH}$ was adjusted to 7 with $10 \mathrm{M}$ sodium hydroxide. The activated carbon was mixed with hydrolysate at ratio $1.5 \mathrm{~g}: 100 \mathrm{~mL}$ for $30 \mathrm{~min}$. The rice straw hydrolysate was obtained after filtration. The concentration of glucose, xylose and arabinose were determined using HPLC (Sritrakul et al. 2017). The HPLC system was equipped with an Aminex HPX-87P (Bio-Rad Labs; Hercules, CA, USA) and a refractive index detector (Waters; Mildford, MA, USA). The column was operated at $80^{\circ} \mathrm{C}$ and $0.60 \mathrm{~mL} / \mathrm{min}$ using a mobile phase of filtered deionized. Furfural and HMF were measured using HPLC with an ultraviolet/visible detector (Waters; Mildford, MA, USA). The Aminex HPX-87H operating at $60^{\circ} \mathrm{C}$ with $5 \mathrm{mM} \mathrm{H}_{2} \mathrm{SO}_{4}$ as a mobile phase $(0.6$ $\mathrm{mL} / \mathrm{min})$, was used for separation. Detection was performed at $280 \mathrm{~nm}$. Acetic acid was analyzed using HPLC with a refractive index detector and the Aminex $\mathrm{HPX}-87 \mathrm{H}$ column maintained at $60^{\circ} \mathrm{C}$ with a flow rate of $0.6 \mathrm{~mL} / \mathrm{min}$ and $\mathrm{H}_{2} \mathrm{SO}_{4}$ as the mobile phase.

Reducing sugar was analyzed by DNS method (Miller 1959). $2 \mathrm{~mL}$ of the sample was mixed with $2 \mathrm{~mL}$ of 3,5Dinitrosalicylic acid (DNS) reagent, boiled for $5 \mathrm{~min}$ in boiling water, cooled and measured the absorbance at a wavelength of $540 \mathrm{~nm}$. Glucose was used as standard for calculation.

Phenolic compound was measured by Folin ciocalteau method (Singleton and Rossi 1965). $0.05 \mathrm{~mL}$ of the sample was mixed with $2 \mathrm{~mL}$ of saturated sodium carbonate solution and $2.5 \mathrm{~mL}$ of $1: 10$ diluted Folin ciocalteau reagent, incubated at $45^{\circ} \mathrm{C}$ for $30 \mathrm{~min}$. The absorbance was measured at $765 \mathrm{~nm}$, and the phenolic content was calculated using vanillic acid as standard solution.

\section{PHA production on glucose and rice straw hydrolysate}

The selected isolates were evaluated for PHA production using $2 \%$ glucose or $10 \%$ rice straw hydrolysate $(0.2 \%$ sugar hydrolysate) as carbon sources. The test was carried out using synthetic N-limiting medium (SNL) $\begin{array}{llllll}\text { (containing } & (\mathrm{g} / \mathrm{L}) & \mathrm{KH}_{2} \mathrm{PO}_{4} & 1.0, & \mathrm{MgSO}_{4} 7 \mathrm{H}_{2} \mathrm{O} & 0.5 \text {, }\end{array}$ $\left(\mathrm{NH}_{4}\right)_{2} \mathrm{SO}_{4} 2.0$, yeast extract 0.5 , fatty acid (oleic acid) 1.0 , carbon source) in shaking flask at $30^{\circ} \mathrm{C}$, for 6 days (AbdEl-Haleem et al. 2007b; Pirozzi et al. 2014).

\section{Extraction and quantitative analysis of PHA}

The cell pellet was centrifuged and washed twice with distilled water. PHA was extracted from cell mass by chloroform-soxhlet extraction method (Pirozzi et al. 2014). The cell was ruptured by toluene solution by vigorous mixing and then centrifuged at $12,000 \mathrm{rpm}$ for $15 \mathrm{~min}$. The pellet was washed with distilled water, acetone and ethanol, respectively. Then the pellet was dissolved in chloroform, and incubated at $50^{\circ} \mathrm{C}$ for $16 \mathrm{~h}$. PHA was extracted by chloroform in soxhlet apparatus for $2 \mathrm{~h}$ and chloroform was vacuum evaporated.

PHA content was analyzed by crotonic acid assay (Law and Slepecky 1961). PHA was dissolved in sulfuric acid and incubated at $100^{\circ} \mathrm{C}$ for $10 \mathrm{~min}$. The absorbance was measured at $235 \mathrm{~nm}$, and PHA content was calculated using 3-hydroxybutyrate (PHB) as standard (Thammasittirong et al. 2017).

$$
\text { PHA content }(\%)=\frac{\mathrm{PHA}(\mathrm{g} / \mathrm{L})}{\mathrm{CDW}(\mathrm{g} / \mathrm{L})} \times 100
$$




\section{RESULTS AND DISCUSSION}

\section{Isolation and screening}

Results revealed that a total of 84 isolates were obtained from different regions of Thailand (Table 1). Screening results of PHAs accumulation using Nile-red assay showed that 37 isolates gave positive results (1 yeast isolate and 36 bacterial isolates). Under the UV transilluminator, five isolates (Y1, B1, B2, B3 and B4) exhibited strong fluorescence signals in comparison to other isolates (Figure 1). The red fluorescence of Nile red is shown to be strongly positive only with hydrophobic compounds such as PHA and lipids. Nile-red is intended to express intracellular lipid particles. It does not react with any tissue component except by solution and can be detected by fluorescence spectroscopy. This fluorescence depends on cell age and the amount of PHA accumulated inside the cell (Spiekermann et al. 1999).

\section{Morphological identification}

The results showed that isolate Y1 was identified as Candida tropicalis with $94 \%$ identity (Table 2). The colony and cell morphology of bacterial isolates were observed under microscope (Figure 1) and subjected to BlastN analysis of $16 \mathrm{~S}$ ribosomal RNA nucleotide sequence. The results exhibited that the isolates $\mathrm{B} 1, \mathrm{~B} 2, \mathrm{~B} 3$, and $\mathrm{B} 4$ were identified as Enterobacter cloacae, Enterobacter carcerogenus, Escherichia coli and Klebsiella pneumonia with $99 \%$ identity, respectively (Table 2).

\section{Rice straw hydrolysate preparation}

Rice straw hydrolysate was prepared by digesting $100 \mathrm{~g}$ of rice straw with $2 \%$ sulfuric acid, containing $22.03 \mathrm{~g} / \mathrm{L}$ of reducing sugar, $2.67 \mathrm{~g} / \mathrm{L}$ glucose, $>10 \mathrm{~g} / \mathrm{L}$ xylose, $3.59 \mathrm{~g} / \mathrm{L}$ arabinose, $0.47 \mathrm{~g} / \mathrm{L}$ phenolic compounds, $0.07 \mathrm{~g} / \mathrm{L}$ acetic acid, $0.0096 \mathrm{~g} / \mathrm{L} \mathrm{HMF}$ and $0.4285 \mathrm{~g} / \mathrm{L}$ furfural (Table 3). The results obtained were similar to the rice straw hydrolysate in the other experiments of Brazilian researchers (Fonseca et al. 2013). When detoxifying rice straw hydrolysate with activated carbon, it was found that the amount of reducing sugar, glucose, arabinose, phenolic compound, HMF and furfural decreased by 7.4, 5.24, 5.57, 100, 95.8 and $99.95 \%$, respectively. This revealed that detoxification with activated carbon showed negative effect on sugar concentration but it was effective in removing toxic compounds. Similar results were also observed by Lanka et al. (2011) and Yadav et al. (2011). The detoxified rice straw hydrolysate contained $20.04 \mathrm{~g} / \mathrm{L}$ of reducing sugar, $2.53 \mathrm{~g} / \mathrm{L}$ glucose, $>10 \mathrm{~g} / \mathrm{L}$ xylose, $3.39 \mathrm{~g} / \mathrm{L}$ arabinose, $0.06 \mathrm{~g} / \mathrm{L}$ acetic acid, <0.0004 g/L HMF and $0.0002 \mathrm{~g} / \mathrm{L}$ furfural (Table 3 ). The result clearly showed that detoxified rice straw hydrolysate can be used in the PHA production. The detoxified rice straw hydrolysate was clear liquid, without any impurities. It can be used in PHA production because the lower impurity makes it easier to separate/purify PHA from fermentation broth than using contaminated waste. This could reduce the cost of PHA purification in process (Anjum et al. 2016; Pakalapati et al. 2018).

Table 1. Sources and number of PHA producing isolates

\begin{tabular}{lccc}
\hline Provinces & $\begin{array}{c}\text { Number } \\
\text { of } \\
\text { isolates }\end{array}$ & $\begin{array}{c}\text { Number of } \\
\text { PHA } \\
\text { producing } \\
\text { yeast }\end{array}$ & $\begin{array}{c}\text { Number } \\
\text { of PHA } \\
\text { producing } \\
\text { bacteria }\end{array}$ \\
\hline Chonburi & 7 & - & 6 \\
Chachoengsao & 5 & - & 2 \\
Rayong & 4 & - & 3 \\
Chanthaburi & 6 & - & - \\
Trat & 7 & - & 5 \\
Prachinburi & 4 & - & 3 \\
Sa Kaeo & 7 & - & - \\
Lampang & 8 & - & 2 \\
Phuket & 13 & - & 11 \\
Phra Nakhon Si & 8 & - & - \\
Ayutthaya & 12 & 1 & 4 \\
Khon Kaen & 3 & - & - \\
Ratchaburi & 84 & 1 & 36 \\
Total & & & \\
\hline
\end{tabular}

Table 2. BlastN result of the selected isolates

\begin{tabular}{clc}
\hline Isolates & \multicolumn{1}{c}{ BlastN results } & $\begin{array}{c}\text { Identities } \\
(\%)\end{array}$ \\
\hline Y1 & $\begin{array}{l}\text { KC597824.1 Candida tropicalis } \\
\text { strain KY7 }\end{array}$ & 94 \\
B1 & $\begin{array}{l}\text { CP010384.1 Enterobacter cloacae } \\
\text { strain 34399 }\end{array}$ & 99 \\
AB776827.1 Enterobacter & 99 \\
B2 & $\begin{array}{l}\text { KC013977.1 Escherichia coli strain } \\
\text { B3 }\end{array}$ & 99 \\
Boh1 & $\begin{array}{l}\text { CP010361.1 Klebsiella pneumonia } \\
\text { strain 32192 }\end{array}$ \\
\hline
\end{tabular}

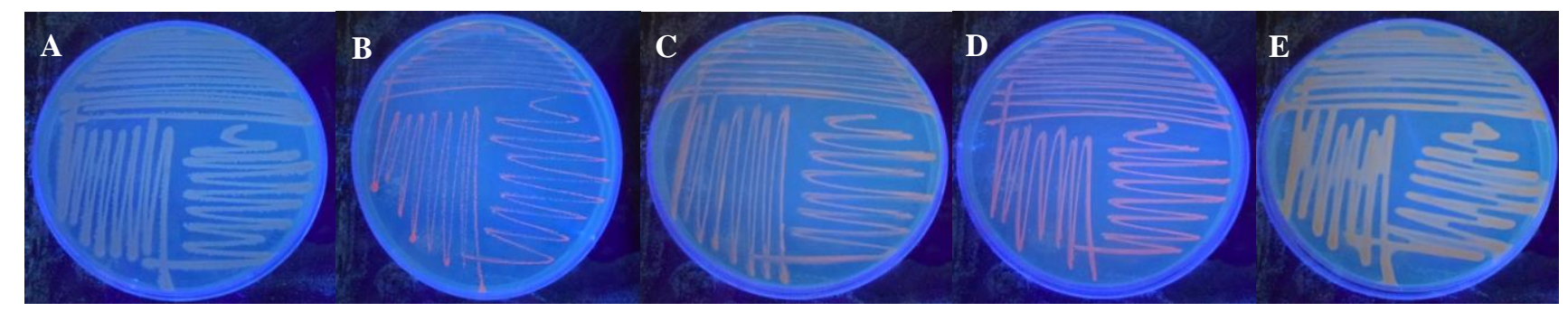

Figure 1. Pink/orange fluorescence under UV light indicates PHA producer isolates Y1, B1, B2, B3, and B4. A: Isolate Y1 (Candida tropicalis), B: Isolate B1 (Enterobacter cloacae), C: Isolate B2 (Enterobacter carcerogenus), D: Isolate B3 (Escherichia coli), E: Isolate B4 (Klebsiella pneumonia) 
Table 3. Chemical analysis of rice straw hydrolysate

\begin{tabular}{lcccccccc}
\hline \multicolumn{1}{c}{ Processes } & $\begin{array}{c}\text { Reducing } \\
\text { sugar }(\mathbf{g} / \mathbf{L})\end{array}$ & $\begin{array}{c}\text { Glucose } \\
(\mathbf{g} / \mathbf{L})\end{array}$ & $\begin{array}{c}\text { Xylose } \\
(\mathbf{g} / \mathbf{L})\end{array}$ & $\begin{array}{c}\text { Arabinose } \\
(\mathbf{g} / \mathbf{L})\end{array}$ & $\begin{array}{c}\text { Phenolic } \\
\text { compounds } \\
(\mathbf{g} / \mathbf{L})\end{array}$ & $\begin{array}{c}\text { Acetic acid } \\
(\mathbf{g} / \mathbf{L})\end{array}$ & HMF(g/L) & Furfural(g/L) \\
\hline Acid hydrolysis & 22.03 & $2.67 \pm 0.01$ & $>10$ & $3.59 \pm 0.05$ & 0.47 & $0.07 \pm 0.00$ & $0.0096 \pm 0.0001$ & $0.4285 \pm 0.0005$ \\
$\begin{array}{l}\text { Activated carbon } \\
\text { treatment }\end{array}$ & 20.04 & $2.53 \pm 0.11$ & $>10$ & $3.39 \pm 0.28$ & 0 & $0.06 \pm 0.00$ & $<0.0004$ & $0.0002 \pm 0.0000$ \\
\hline
\end{tabular}

Table 4. Production of PHA by selected isolates

\begin{tabular}{lcc}
\hline & \multicolumn{2}{c}{ PHA content (\%) } \\
\cline { 2 - 3 } Isolates & $\begin{array}{c}\text { SNL with 2\% } \\
\text { glucose }\end{array}$ & $\begin{array}{c}\text { SNL with 10\% } \\
\text { rice straw } \\
\text { hydrolysate }\end{array}$ \\
\hline Candida tropicalis (Y1) & 0.64 & 2.62 \\
Enterobacter cloacae (B1) & 1.30 & 2.76 \\
Enterobacter carcerogenus (B2) & 0.72 & 5.38 \\
Escherichia coli $(\mathrm{B} 3)$ & 1.65 & 3.66 \\
Klebsiella pneumonia $(\mathrm{B} 4)$ & 0.38 & 0.44 \\
\hline
\end{tabular}

PHA production on glucose and rice straw hydrolysate

The PHA production by Candida tropicalis (Y1), Enterobacter cloacae (B1), Enterobacter carcerogenus (B2), Escherichia coli (B3), Klebsiella pneumonia (B4) were $0.64,1.30,0.72,1.65,0.38 \%$ on SNL with $2 \%$ glucose and $2.62,2.76,5.38,3.66,0.44 \%$ on SNL with $10 \%$ rice straw hydrolysate. The isolate $\mathrm{B} 3$ and $\mathrm{B} 2$ showed the highest PHA production in SNL with $2 \%$ glucose and $10 \%$ rice straw hydrolysate, respectively. Interestingly, all isolates showed higher PHA production in $10 \%$ rice straw hydrolysate than $2 \%$ glucose (Table 4 ) but the rice straw hydrolysate contained 10 times less reducing sugar than SNL with $2 \%$ glucose. It was observed that rice straw hydrolysate contained other nutrients that could promote PHA formation in microorganisms. Silva et al. (2013) reported that rice straw hydrolysate obtained by digesting rice straw with sulfuric acid contained xylose, glucose, arabinose and minerals such as potassium, iron, manganese, chromium, aluminum, sodium, zinc and copper. These nutrients could help to promote the production of PHA in microorganisms. The result was comparable with the previous reports that Candida norvegensis C-Y8 (Aba-El-Haleem et al. 2007a), Enterobacter cloacae SU-1 (Samrot et al. 2011), Klebsiella pneumonia (Feng et al. 2015) and Escherichia coli (Qi et al. 1998) can produce PHA at different level depending on the culture condition. However, the result was very promising for biotechnological application when using rice straw hydrolysate as the sole carbon source. The PHA content of the selected strains grown on rice straw hydrolysate were higher than that on glucose. Rice straw hydrolysate has more nutrients than glucose only, and hence microorganisms can grow, utilizing the nutrients present in rice straw hydrolysate, and convert them into valuable compounds and polymers. Ahn et al. (2015) reported that rice straw hydrolysate has carbon to nitrogen ratio ( $\mathrm{C} / \mathrm{N}$ ratio) which could stimulate the PHA accumulation in Cupriavidus necator. With this concept, researchers have reported PHA production from biomass or various wastes. Polyhydroxybutyrate (PHB) is produced from community wastewater with Enterobacter aerogens 12Bi strain (Ceyhan and Ozdemir 2011). Javaid et al. (2020) reported PHA production from waste, such as wood chips, cardboard cutouts, plastic bottle cutouts, shredded polystyrene cups and plastic bags, using Stenotrophomonas maltophilia HA-16 with good yield. The bacterial isolates B2 (Enterobacter carcerogenus) could be considered as potential strain for the conversion of rice straw hydrolysate into PHA. The selected isolate utilized rice straw hydrolysate as sole carbon source for growth, PHA biosynthesis, and accumulating PHA 5.38\%. However, other isolates also showed a promising result in PHA production.

In conclusion, these isolates could be considered good candidates for industrial production of PHA from lignocellulosic biomass. Currently, these strains need to be further investigated for optimization of the fermentation parameters to increase the productivity of PHA and make the whole process more cost-effective.

\section{ACKNOWLEDGEMENTS}

This work was supported by the Higher Education Research Promotion and National Research University project of Thailand, office of the Higher Education Commission.

\section{REFERENCES}

Aba-El-Haleem DAM, Zaki SA, Abuelhamd AT, Amara A, Aboelreesh GMS. 2007a. Biosynthesis of polyhydroxyalkanotes. J Appl Sci Environ Manage 11: 5-10. DOI: 10.4314/jasem.v11i3.55066.

Abd-El-Haleem DAM, AlMa'adeed MA, Al-Thani N. 2007b. Physical and chemical properties of polyhydroxyalkanotes biodegradable polymers produced in transgenic yeasts. Glob J Environ Res 2: 69-73.

Abd-El-Haleem DAM. 2009. Biosynthesis of polyhydroxyalkanotes in wild yeasts. Pol J Micro 58: 37-41.

Ahn J, Jho EH, Nam K. 2015. Effect of $\mathrm{C} / \mathrm{N}$ ration on polyhydroxyalkanoates (PHA) accumulation by Cupriavidus necator and its implication on the use of a rice straw hydrolysates. Environ Eng Res 20: 246-253. DOI: 10.4491/eer.2015.055.

Amache R, Sukan A, Safari M, Roy I, Keshavarz T. 2013. Advances in PHAs production. Chem Eng Trans 32: 931-936.

Anjum A, Zuber M, Zia KM, Noreen A, Anjum MN, Tabasum S. 2016. Microbial production of polyhydroxyalkanoates (PHAs) and its copolymers: A review of resent advancements. Intl J Biol Macromol 89: 161-174. DOI: 10.1016/j.ijbiomac.2016.04.069. 
Ceyhan N, Ozdemir G. 2011. Poly- $\beta$-hydroxybutyrate (PHB) production from domestic wastewater using Enterobacter aerogenes $12 \mathrm{Bi}$ strain. Afr J Microbiol Res 5: 690-702.

Ciesielski S, J Mozejko, N Pisutpaisal. 2015. Plant oils as promising substrates for polyhydroxyalkanoates. J Cleaner Prod 106: 408-421. DOI: 10.1016/j.jclepro.2014.09.040.

Folino A, Karageorgiou A, Calabro PS, Komilis D. 2020. Biodegradation of wasted bioplastics in natural and industrial environments: A review. Sustainability 12: 6030. DOI: 103390/su12156030.

Feng X, Xian M, Liu W, Xu C, Zhang H, Zhao G. 2015. Biosynthesis of poly(3-hydroxypropionate) from glycerol using engineered Klebsiella pneumoniae strain without vitamin B12. Bioengineered 6: 77-81. DOI: 10.1080/21655979.2015.1011027.

Fonseca BG, Puentes JG, Mateo S, Sánchez S, Moya AJ, Roberto IC. 2013. Detoxification of rice straw and olive tree pruning hemicellulosic hydrolysates employing Saccharomyces cerevisiae and its effect on the ethanol production by Pichia stipitis. J Agric Food Chem 61: 9658-9665. DOI: 10.1021/jf402474s.

Javaid H, Nawaz A, Riaz N, Mukhtar H, Haq IU, Shah KA, Khan H, Naqvi SM, Shakoor S, Rasool A, Ullah K, Manzoor R, Kaleem I, Murtaza G. 2020. Biosynthesis of Polyhydroxyalkanoates (PHAs) by the valorization of biomass and synthetic Waste. Molecules 25: 5539. DOI: $10.3390 /$ molecules25235539.

Karan H, Funk C, Grabert M, Oey M, Hankamer B. 2019. Green bioplastics as part of a circular bioeconomy. Trends Plant Sci 24 237-249. DOI: 10.1016/j.tplants.2018.11.010.

Lanka S, Adivikatia V, Shaik N, Kothauni SY, Panda SH, Venumula GP, Linga VR. 2011. Studies on different detoxification method for the acid hydrolysate of lignocellulosic substrate Saccharum spontaneum. Dyn Biochem Proc Biotecnol Mol Biol 5: 53-57.

Law JH, Slepecky RA. 1961. Assay of Poly- $\beta$-Hydroxybutyric Acid. J Bacteriol 82: 33-36. DOI: 10.1128/jb.82.1.33-36.1961.

Martı'nez-Gutie'rrez CA, Latisnere-Barraga'n H, Garcı'a-Maldonado JQ, Lo'pez-Corte's A. 2018. Screening of polyhydroxyalkanoateproducing bacteria and $\mathrm{PhaC}$-encoding genes in two hypersaline microbial mats from Guerrero Negro, Baja California Sur, Mexico. PeerJ 6: e4780. DOI: $10.7717 /$ peerj.4780.

Miller GL. 1959. Use of dinitrosalicylic acid reagent for determination of reducing sugar. Anal Chem 31: 426-428. DOI: 10.1021/ac60147a030.

Pakalapati H, Chang CK, Show PL, Arumugasamy SK, Lan JCW. 2018 Development of polyhydroxyalkanoates production from waste feedstocks and applications. J Biosci Bioeng 126: 282-292. DOI: 10.1016/j.jbiosc.2018.03.016.
Pirozzi D, Ausiello A, Yousuf A, Zuccaro G, Toscano G. 2014 Exploitation of oleaginious yeasts for the production of microbial oils from agricultural biomass. Chem Eng Trans 37: 469-474. DOI: 10.3303/CET1437079.

Qi Q, Steinbuchel A, Rehm BHA. 1998. Metabolic routing towards polyhydroxyalkanoic acid synthesis in recombinant Escherichia coli $(f a d R)$ : Inhibition of fatty acid $\beta$-oxidation by acrylic acid. FEMS Microbiol Lett 167: 89-94. DOI: 10.1111/j.15746968.1998.tb13212.x.

Samrot AV, Avinesh RB, Sukeetha SD, Senthilkumar P. 2011. Accumulation of poly [(R)-3-hydroxyalkanoates] in Enterobacter cloacae SU-1 during growth with two different carbon sources in batch culture. Appl Biochem Biotechnol 163: 195-203. DOI: 10.1007/s12010-010-9028-7.

Singleton VL, Rossi JA. 1965. Colorimetry of total phenolics with phosphomolybdic-phosphotungstic acid reagents. Am J Enol Vitic 16: 144-158

Silva JPA, Carneiro LM, Roberto IC. 2013. Treatment of rice straw hemicellulosic hydrolysates with advanced oxidative processes: A new and promising detoxification method to improve the bioconversion process. Biotechnol Biofuels 6: 23. DOI: 10.1186/1754-6834-6-23.

Sritrakul N, Nitisinprasert S, Keawsompong K. 2017. Evaluation of dilute acid pretreatment for bioethanol fermentation from sugarcane bagasse pith. Agri Nat Res 51: 512-519. DOI: 10.1016/j.anres.2017.12.006

Spiekermann P, Rehm BHA, Kalscheuer R, Baumeister D, Steinbuchel A. 1999. A sensitivity, viable-colony staining method using Nile red for direct screening of bacteria that accumulate polyhydroxyalkanoic acids and other lipid storage compounds. Arch Microbiol 171: 73-80. DOI: $10.1007 / \mathrm{s} 002030050681$.

Tan WA, Wijaya I, Purwadaria T. 2019. Bioprospecting of polyhydroxyalkanoates-producing bacteria from Indonesian marine environment. Biodiversitas 20: 1309-1315. DOI: 10.13057/biodiv/d200521.

Thammasittirong A, Saechow S, Na-Ranong Thammasittirong S. 2017. Efficient polyhydroxybutyrate production from Bacillus thuringiensis using sugarcane juice substrate. Turk J Biol 41: 992-1002. DOI: 10.3906/biy-1704-13.

Yadav KS, Naseeruddin S, Prashanthi GS, Sateesh L, Rao LV. 2011. Bioethanol fermentation of concentrated rice straw hydrolysate using co-culture of Saccharomyces cerevisiae and Pichia stipites. Bioresour Technol 102: 6473-6478. DOI: 10.1016/j.biortech.2011.03.019. 